\title{
Ion Beam Induced Strain Relaxation in Pseudomorphous Epitaxial SiGe Layers
}

\author{
A.F. Vyatkin, V.S. Avrutin, N.F. Izyumskaya, V.K. Egorov, V.V. Starkov, V.I. Zinenko, \\ Institute of Microelectronics Technology, RAS, 142432, Moscow distr., Chernogolovka, Russia \\ I.A. Smirnova, \\ Institute of Solid State Physics, RAS, 142432, Moscow distr.,Chernogolovka, Russia \\ P.L.F. Hemment, A. Nejim, \\ University of Surrey, Guilford, UK \\ V.I. Vdovin, \\ Institute for Chemical Problems of Microelectronics, Moscow, Russia \\ and T.G. Yugova \\ Institute of Rare Metals, Moscow, Russia
}

\begin{abstract}
The effects of irradiation with $\mathrm{Ge}^{+}$and $\mathrm{Ar}^{+}$ions at elevated temperatures on the relaxation behavior of pseudomorphic $\mathrm{Si}_{1,7 y} \mathrm{Ge}_{0.21} / \mathrm{Si}$ heterostructures have been compared. It was found the strain relaxation in the structures implanted with $\mathrm{Ge}^{+}$ at $400^{\circ} \mathrm{C}$ started already upon implantation. Post-implantation thermal annealing of this sample resulted in considerably higher degree of relaxation than that in control (non-implanted) samples as well as in samples implanted with $\mathrm{Ar}^{+}$both at 230 and $400^{\circ} \mathrm{C}$ and with $\mathrm{Ge}^{+}$at $230^{\circ} \mathrm{C}$. This result points to a dramatic influence of both the implantation temperature and ion species on relaxation behavior of the ion-irradiated heterostructure. Two possible mechanisms for this effect are discussed.
\end{abstract}

\section{INTRODUCTION}

Epitaxial growth of $\mathrm{Si}_{1,} \mathrm{Ge}_{\text {, }}$ on $\mathrm{Si}$ substrates is of increasing interest because it provides a possibility to design new electronic and optical devices. A crucial issue in fabrication of electronic devices based on $\mathrm{SiGe} / \mathrm{Si}$ heterostructures is eliminating threading dislocations [1], which deteriorates the electronic properties of the structures [2]. In recent years, it has been demonstrated that non-equilibrium point defects introduced into heterostructures enhance strain relaxation and can considerably reduce density of threading dislocations [311]. Point defects were introduced by lowering growth temperature, which led to the saturation of the growing layers with point defects [3-8], as well as by low-energy ion bombardment of layers during epitaxial growth [7-9] or after growth [10-13]. It is generally accepted that the accelerated strain relaxation is due to aggregates of point defects acting as sites for nucleation of misfit dislocations. However, particular mechanisms responsible for the strain relaxation in $\mathrm{SiGe} / \mathrm{Si}$ heterostructures supersaturated with point defects are not understood. Besides, the effects of implantation species, implantation temperature, and peak position of the implanted species on the relaxation behavior of $\mathrm{SiGe} / \mathrm{Si}$ heterostructures have receive rather little attention. In this paper, we report on the effect of implantation temperature and ion species on the strain relaxation in $\mathrm{SiGe} / \mathrm{Si}$ heterostructures.

\section{EXPERIMENTAL}

$\mathrm{Si}_{0.73} \mathrm{Ge}_{0.21}$ layer was grown on $\mathrm{Si}(100)$ wafer doped with boron to the concentration $1.3 \times 10^{15} \mathrm{~cm}^{-3}$ by solid-source MBE. The wafer was chemically precleaned ex situ by the standard procedure [14] and immediately introduced into the load-lock chamber of the MBE machine. A protecting $\mathrm{SiO}_{2}$ layer was removed in situ by heating to $850^{\circ} \mathrm{C}$ in a weak $\mathrm{Si}$ beam followed by a temperature flash at $1000^{\circ} \mathrm{C}$ for $1 \mathrm{~min}$. The base pressure in the growth chamber was $10^{\text {"11 }}$ Torr, during deposition the pressure rose to $4 \times 10^{-1}$ Torr. The undoped pseudomorphic $\mathrm{Si}_{0.77} \mathrm{Ge}_{0.21}$ layer $150 \mathrm{~nm}$ thick was grown at a temperature of $450^{\circ} \mathrm{C}$ and a rate of about $0.1 \mathrm{~nm} / \mathrm{s}$. This thickness of the SiGe layer was chosen to avoid strain relaxation during the growth. The film composition was determined by $x$-ray diffraction measurements. The Ge content varied over the substrate within $2 \%$. Then, the wafer was scribed into samples about $2 \times 2 \mathrm{~cm}$ in dimensions.

The samples were implanted with $130-\mathrm{keV} \mathrm{Ar}^{+}$or $200-\mathrm{keV}$ $\mathrm{Ge}^{+}$ions at $230^{\circ} \mathrm{C}$ or $400^{\circ} \mathrm{C}$ to doses of $10^{14}(\mathrm{Ar})$ and $5 \times 10^{\text {t. }}$ (Ge) $\mathrm{cm}^{-2}$, respectively. The implantation parameters were chosen so that depth profiles of radiation-induced defects were about the same for $\mathrm{Ar}^{+}$and $\mathrm{Ge}^{+}$ions. The defect profiles were calculated under the Suspre program. The peak positions of the defect profiles were within the SiGe layer, at a depth of $\cong 80 \mathrm{~nm}$. The implanted and as-grown samples were annealed in a vacuum furnace $\left(10^{-6}\right.$ Torr $)$ at temperatures from 450 to $550^{\circ} \mathrm{C}$. The temperature was kept constant at $\pm 2^{\circ} \mathrm{C}$, the absolute temperature accuracy being of about $3^{\circ} \mathrm{C}$.

Chemical Ge profiles were measured by secondary ion mass spectroscopy (SIMS) using a Cameca IMS-4f machine. The depth calibration was performed by measuring crater depths with a Taylor-Hobson Talystep profilometer.

Strain relaxation in the heterostructures was studied by double-crystal $x$-ray diffraction measurements (Rigaku RU200 source) and plan-view transmission electron microscopy (TEM) using a JEOL JEM-200 CX microscope operated at $200 \mathrm{kV}$. The specimens for TEM were prepared by chemical etching from the backside of the heterostructure. From $x$-ray 
diffraction data, the degree of relaxation was calculated by the well-known formula $R=\left(a_{+}^{\text {peseud }}-a_{1}^{r e l}\right) /\left(a_{1}^{\text {pewewd }}-a_{j}\right)$, where $a_{+}{ }_{t}^{\text {rewe }}$ and $a_{+}{ }^{\text {ret }}$ are the out-of-plane lattice constants of pseudomorphic and relaxed SiGe layers, respectively, and $a_{c}$ is the lattice constant of bulk SiGe.

\section{RESULTS AND DISCUSSION}

$\mathrm{X}$-ray diffraction measurements revealed no strain relaxation $(R=0)$ in the as-grown $\mathrm{Si}_{0.79} \mathrm{Ge}_{0.21} / \mathrm{Si}$ structure. The spectra of all the samples measured before and after ion implantation are similar, except for the spectrum of the sample implanted with $\mathrm{Ge}^{+}$at $400^{\circ} \mathrm{C}$, which is noticeably broadened as compared to the spectrum of this sample measured before implantation, although the peak position remains unchanged (Fig. 1, curves 1 and 2). The SIMS data prove that this broadening cannot be explained by interdiffusion of $\mathrm{Si}$ and $\mathrm{Ge}$ at the SiGe/Si interface: the depth profile of Ge remains virtually unchanged upon implantation. Therefore, we attribute this effect to the presence of radiation-induced defect complexes or/and dislocations in the SiGe layer. Indeed, plan-view TEM study revealed a low-density network of misfit dislocations; i.e., strain relaxation started in the sample implanted with $\mathrm{Ge}^{+}$at $400^{\circ} \mathrm{C}$ upon implantation.

$\mathrm{X}$-ray diffraction measurements of the samples annealed at $450^{\circ} \mathrm{C}$ for $15 \mathrm{~min}$ revealed that the degree of relaxation $R$ of the sample implanted with $\mathrm{Ge}^{+}$at $400^{\circ} \mathrm{C}$ is as high as 0.5 , whereas $R=0$ for other samples (control sample, and the samples implanted with $\mathrm{Ge}^{+}$at $230^{\circ} \mathrm{C}$ and with $\mathrm{Ar}^{+}$at $230^{\circ} \mathrm{C}$ and $400^{\circ} \mathrm{C}$ ). As an illustration, Fig. 2 compares plan-view

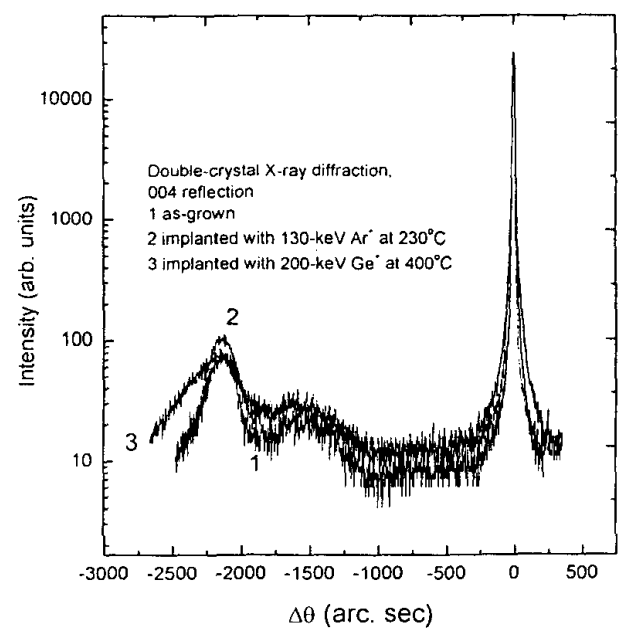

Fig. I. $X$-ray diffraction spectra of ( $/$ ) the as-grown sample, (2) the sample implansted with $\mathrm{Ar}^{+}$at $230^{\circ} \mathrm{C}$, and (3) the sample implanted with $\mathrm{Ge}^{+} \mathrm{at}$ $400^{\circ} \mathrm{C}$. The spectra of the samples implanted with $\mathrm{Ar}^{+}$at $400^{\circ} \mathrm{C}$ and $\mathrm{Ge}^{+}$at $230^{\circ} \mathrm{C}$ are similar to that of the as-arown sample. The weak feature around 1600 arc sec is due to nonumiform film composition.
TEM images of the samples implanted with $\mathrm{Ge}^{+}$at 230 and $400^{\circ} \mathrm{C}$ and then annealed at $450^{\circ} \mathrm{C}$. One can see that the misfit-dislocation network in the second sample is much more dense. Dislocation arcs clearly seen in Fig. $2 b$ indicate that dislocation half-loops propagate into the substrate; i.e., the misfit-dislocation network in the sample implanted with $\mathrm{Ge}^{+}$ at $400^{\circ} \mathrm{C}$ occupies three-dimensional region. Annealing of this sample at $550^{\circ} \mathrm{C}$ for 15 min results in the degree of relaxation of about 0.92 (according to $x$-ray diffraction data) as compared $R=0.47$ for the sample implanted with $\mathrm{Ge}^{+}$at $230^{\circ} \mathrm{C}$.

Thus, relaxation behavior of the sample implanted with $\mathrm{Ge}^{+}$at $400^{\circ} \mathrm{C}$ differs drastically from that of the other samples. In our opinion, there are two explanations for this result. First, dislocation sources existing in the as-grown heterostructure may be activated under these implantation conditions (high temperature and heavy ion species). Second, defect complexes of a specific type may form in the SiGe layer during $\mathrm{Ge}$ implantation at $400^{\circ} \mathrm{C}$. This presumption is supported by the fact that TEM examination of the sample im-

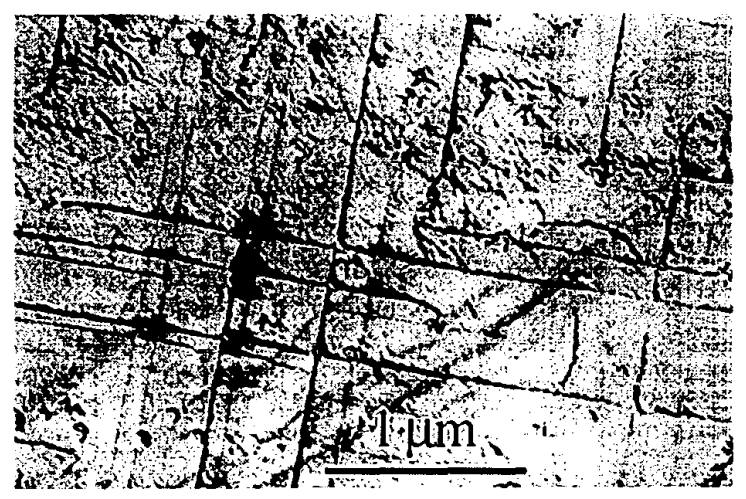

(a)

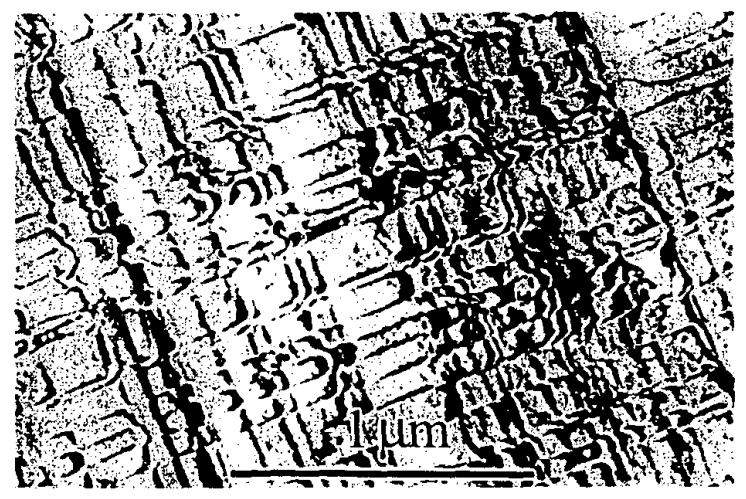

(b)

Fig. 2. Plan-view TEM images of the samples implanted with $\mathrm{Ge}^{+}$at (a) $230^{\circ} \mathrm{C}$ and (b) $400^{\circ} \mathrm{C}$ and annealed at $450^{\circ} \mathrm{C}$. According to $\mathrm{x}$-ray diftraction data, $R=0$ for the first sample, and $R=0.5$ for the second. 
planted with $\mathrm{Ge}^{+}$at $400^{\circ} \mathrm{C}$ and then annealed at $450^{\circ} \mathrm{C}$ revealed the presence of $\mathrm{V}$-shaped defects consisted of two threading $60^{\circ}$-dislocations (Fig. 3). These defects were observed at various depths in the SiGe film. Such a configuration can arise, if these dislocations nucleated on some defects (presumably, complexes of implantation-induced point defects). It seems likely that the defect complexes, which are located at the SiGe/Si interface, can promote the formation of misfit-dislocation network, thus enhancing strain relaxation. Although the depth profiles of radiation-induced point defects are the same for all the samples studied, the V-shaped defects are observed only in the sample implanted with $\mathrm{Ge}^{+}$at $400^{\circ} \mathrm{C}$. This allows us to conclude that rather heavy ions producing dense cascades and sufficiently high implantation temperature providing high diffusion mobility of radiationinduced point defects are essential for the formation of the complexes responsible for the $V$-shaped defects. Further investigations are needed to clarify the nature of these complexes. It is not improbable that the two proposed mechanisms operate concurrently.

\section{CONCLUSION}

The relaxation behavior of pseudomorphic $\mathrm{Si}_{1,79} \mathrm{Ge}_{1,22} / \mathrm{Si}$ heterostructures implanted with $\mathrm{Ge}^{+}$or $\mathrm{Ar}^{+}$ions at $230^{\circ} \mathrm{C}$ or $400^{\circ} \mathrm{C}$ was studied. It was found that the rate of strain relaxation in the sample implanted with $\mathrm{Ge}^{+}$at $400^{\circ} \mathrm{C}$ is noticeably higher than in other samples. Two possible mechanisms for the enhanced relaxation were proposed: (1) activation of existing dislocation sources under ion implantation with heavy ions at elevated temperature and (2) formation of specific

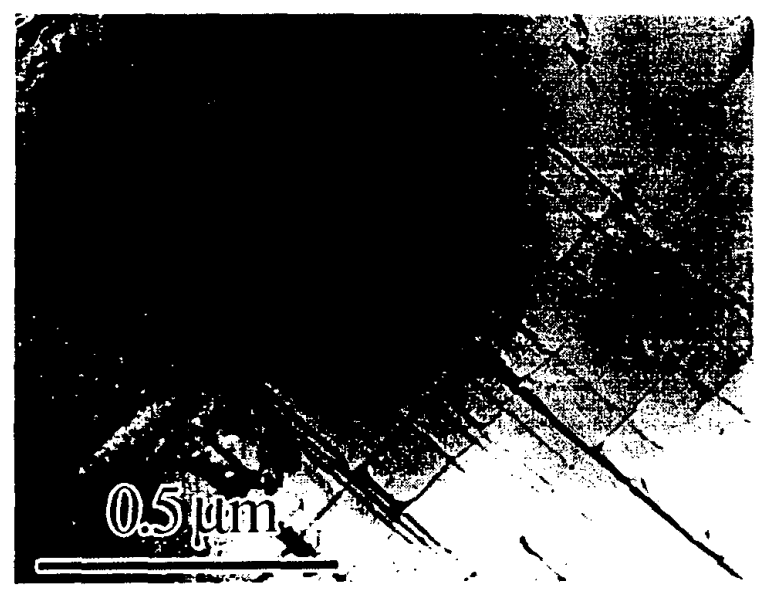

Fig. 3. Plan-view TEM image of the sample implanted with $\mathrm{Ge}^{+}$at $400^{\circ} \mathrm{C}$ and annealed at $450^{\circ} \mathrm{C}$. The micrograph was taken from the region of the oblique section, where the misfit-dislocation network was removed almost completely during the sample preparation. Therefore, the network of misfit dislocations seems less dense than that in Fig. 2b. V-shaped defects consisted of two threading $60^{\circ}$-dislocations are clearly seen in the micrograph. defect complexes acting as nucleation sites for V-shaped dislocations and promoting the formation of the misfitdislocation network. In both cases, heavy ion species and elevated implantation temperature are required to accelerate strain relaxation.

\section{ACKNOWLEDGMENT}

This work was supported by the Russian Foundation for Basic Research, project no. 00-02-18039.

\section{REFERENCES}

[1] A.N. Larsen, "Growth- and process-induced defects in SiGe-based heterostructures," Solid State Phenomena, vol. 69-70, pp. 43-52, 1999

[2] U. Kenig and $\mathrm{J}$. Hersener, "Needs of low thermal budget processing in SiGe technology," Solid State Phenomena, vol. 47-48, pp. 17-32. 1996.

[3] K.K. Lindner, F.C. Zhang, J.-S. Rieh, P. Bhattacharya, and D. Houghton. "Reduction of dislocation density in mismatched SiGe/Si using a lowtemperauture Si Buffer layer," Appl. Phys. Lett. vol. 70, 3224-3226. 1997.

[4] 1.H. Li, C.S. Peng, Y. Wu, D.Y. Dai, I.M. Zhou, and Z.H. Mai, "Relaxed $\mathrm{Si}_{0.7} \mathrm{Ge}_{0.3}$ layers grown on low-temperature $\mathrm{Si}$ buffers with low threading dislocation density," Appl. Phys. Lell., vol. 71, pp. 3132-3134. 1997.

[5] C.S. Peng, Z.Y. Zhao, H. Chen, J.H. Li, Y.K. Li, L.W.Guo, D. Y. Dai, Q Huang, J.M. Zhou, Y.H. Zhang, T.T. Sheng, and C.H. Tung, "Relaxed $\mathrm{Si}_{0,9} \mathrm{Ge}_{0.1}$ alloy layers with low threading dislocation densities grown on low-temperature Si buffers," Appl. Phys. Lett., vol. 72, pp. 3160-3162, 1998.

[6] C.S. Peng, H. Chen, Z.Y. Zhao, J.H. Li, D.Y. Dai, Q. Huang, J.M. Zhou, Y.H. Zhang, C.H. Tung, T.T. Sheng, and J. Wang, "Strain relaxation of GeSi alloy with low dislocation density grown on low-temperature $\mathrm{Si}$ buffers," J. Cryst. Growth, vol. 201/202, pp. 530-533, 1999.

[7] E.Kasper, K.Lyutovich, M.Bauer, and M.Oehme, "New virtual substrate concept for vertical MOS transistors," Thin Solid Films. vol. 336, pp. 319-322, 1998

[8] K.Lyutovich, F.Ernst, E.Kasper, M.Bauer, and M.Oehme, "Interaction between point defects and dislocations in SiGe," Solid State Phenomena, vol. 69-70, pp. 179-184, 1999.

[9] M. Bauer, M. Oehme, K. Lyutovich, and E. Kasper, "Ion assisted MBE growth of SiGe nanostructures," Thin Solid Films, vol. 336. pp. 104$108,1998$.

[10] S. Mantl. B. Hollander. R. Liedtke. S. Mester. H.1. Herzog. H. Kibbcl. and T. Hackbarth, "Strain relaxation of epitaxial SiGe layers on Si(100) improved by hydrogen implantation." Nucl. Instrum. Methods Phys. Res, vol. B147. pp. 29-34, 1999.

[11] B. Hollander, S. Mantl, R. Liedtke, S. Mester, H.J. Herzog, H. Kibbel. and T. Hackbarth, "Enhanced strain relaxation of epitaxial SiGe layers on $\mathrm{Si}(100)$ after $\mathrm{H}^{+}$ion implantation," Nucl. Instrum. Methods Phys Res, vol. B148, pp. 200-205, 1999.

[12] R. Hull, E.A. Stach, R. Tromp, F. Ross, and M. Reuter, "Interactions of" moving dislocations in semiconductors with point, line, and planar defects," Phys. Status Solidi (a), vol. 171. pp. 133-145, 1999.

[13] E.A. Stach, R. Hull, J.C. Bean, K.S. Jones, and A. Nejim, "In situ studies of the interaction of dislocations with point defects during annealing of ion implanted Si/SiGe/Si(001) heterostructures." Microsc. Microanal., vol. 4, pp. 294-307, 1998.

[14] R.C.Henderson, "Silicon cleaning with hydrogen peroxide solutions: a high energy electron diffraction and Auger electron spectroscopy study. J. Electochem. Soc., vol. 119, pp. 772-775, 1972. 